\title{
Recomendações para remodelação dos processos de desinfecção de efluentes no Brasil - Um alerta deflagrado pela pandemia COVID-19
}

\author{
Recommendations for the remodeling of sewage disinfection processes in Brazil - a concern
}

brought by the COVID-19 pandemic

Recomendaciones para la remodelación de procesos de desinfección de aguas residuales en Brasil -

Una alerta de la pandemia COVID-19

Recebido: 05/02/2021 | Revisado: 08/02/2021 | Aceito: 12/02/2021 | Publicado: 19/02/2021

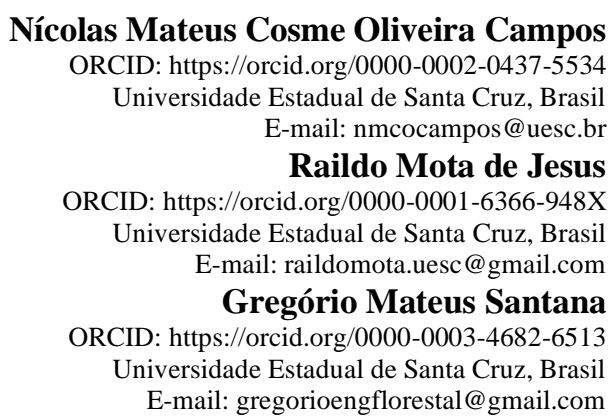

\section{Resumo}

A vulnerabilidade denotada pela pandemia causada pelo SARS-CoV-2, deflagrou na população mundial preocupação em estabelecer medidas de contenção emergencial. Embora, até o momento, poucos estudos estabeleçam o esgoto sanitário como via de contaminação do SARS-CoV-2, no Brasil a instabilidade de destinação dos efluentes, estabeleceu um alerta acerca da incapacidade dos sistemas públicos de proverem a implementação de captação e tratamento adequado dos efluentes domésticos. Este artigo apresenta evidencias em base de dados cientificas eletrônicas nacionais e internacionais que corroboram uma pluralidade de tecnologias emergentes de desinfecção de águas residuais aplicáveis, eficientes e seguras para desinfecção dos efluentes em suas etapas de tratamento, prevenindo o despejo de dejetos potencialmente contaminados no meio ambiente. Colaborando com a mitigação de doenças e com a necessária remodelação dos processos de desinfecção de efluentes, considerando os recursos e a realidade brasileira.

Palavras-chave: Sars-CoV-2; Tratamento de efluentes; Técnicas de desinfecção de efluentes; Saneamento básico.

\begin{abstract}
The vulnerability shown by the pandemic caused by SARS-CoV-2, sparked a concern in the world population in establishing emergency containment measures. Although, so far, few studies have established sanitary sewage as a way of contamination by SARS-CoV-2, in Brazil the instability of wastewater disposal has established a warning about the inability of public systems to provide the implementation of collection and adequate treatment domestic effluents. This article presents evidence in national and international electronic scientific databases that corroborate a plurality of emerging technologies for the disinfection of applicable, efficient and safe wastewater for the disinfection of effluents in their treatment stages, preventing the discharge of potentially contaminated waste into the environment. Collaborating with disease mitigation and the necessary remodeling of effluent disinfection processes, considering the resources and the Brazilian reality.
\end{abstract}

Keywords: Sars-CoV-2; Sewage treatment; Sewage disinfection techniques; Basic sanitation.

\section{Resumen}

La vulnerabilidad mostrada por la pandemia provocada por el SARS-CoV-2, despertó la preocupación de la población mundial en el establecimiento de medidas de contención de emergencia. Si bien, hasta el momento, pocos estudios han establecido las aguas residuales sanitarias como una vía de contaminación por SARS-CoV-2, en Brasil la inestabilidad de la disposición de aguas residuales ha establecido una advertencia sobre la incapacidad de los sistemas públicos para brindar la implementación de recolección y tratamiento doméstico adecuado. efluentes. Este artículo presenta evidencias en bases de datos científicas electrónicas nacionales e internacionales que corroboran una pluralidad de tecnologías emergentes para la desinfección de aguas residuales aplicables, eficientes y seguras para la desinfección de efluentes en sus etapas de tratamiento, evitando el vertido de residuos potencialmente contaminados 
al medio ambiente. Colaborar con la mitigación de enfermedades y la necesaria remodelación de los procesos de desinfección de efluentes, considerando los recursos y la realidad brasileña.

Palabras clave: SARS-CoV-2; Tratamiento de aguas residuales; Técnicas de desinfección de efluentes; Saneamiento.

\section{Introdução}

Desde a detecção de casos de pneumonia, em Hubei, China, até a sua definição como pandemia pela OMS em 1 de dezembro de 2019, a COVID-19, doença infecciosa causada pelo novo coronavírus da síndrome respiratória aguda (SARSCoV-2), foi capaz de impactar todo o panorama econômico, ambiental, político e social em escala global (Fernandes, 2020), trazendo à tona crises nos mais variados seguimentos da economia (Komatsu; Menezes-Filho, 2020).

O mecanismo de transmissão do vírus SARS-CoV-2 ocorre por vias respiratórias através do contato das mucosas com gotículas de saliva expelidas pela respiração nasal ou bucal de portadores do vírus, não necessitando que o portador esteja necessariamente sintomático (World Health Organization, 2020). Wigginton e Boehm (2020), admitem que se sabe pouco sobre como o Sars-CoV-2, se dissemina pelo ambiente, apontando a variabilidade encontrada dentro da família Coronaviridae, interferindo diretamente em suas vias de disseminação.

Neste cenário, quando inicialmente descoberta a presença do SARS-CoV-2 em águas residuais, aventou-se a possibilidade de transmissibilidade do vírus por vias hídricas, especialmente em comunidades que não possuem amplo acesso ao abastecimento e saneamento adequado (Daughton, 2020). No Brasil, infere ser salutar para o aspecto de estabilidade dos sistemas de saúde públicos e redução da transmissão e enfrentamento da pandemia de COVID-19, que as medidas de controle associem saúde pública, saúde ambiental e saneamento básico (Prado et al., 2020).

A expansão urbana desordenada no Brasil e a incapacidade dos sistemas públicos de saneamento de proverem a implementação de sistemas de captação e tratamento adequado dos efluentes domésticos, segundo De Mello et al. (2020), impõem dificuldades ao acesso à recursos de higiene potencializando a contaminação por patógenos (Uhr; Schmechel; Uhr, 2020), em especial nas comunidades periféricas dos municípios brasileiros (Paiva; Souza; 2018).

Considerando o alerta deflagrado pela pandemia do COVID-19 no país, que despertou a reflexão de estudos de processos viáveis de desinfecção de águas residuais sob as características estruturais sanitárias do Brasil, o presente artigo objetiva levantar processos eficientes, acessíveis e seguros para desinfecção dos efluentes em suas etapas de tratamento, prevenindo o despejo de dejetos potencialmente contaminados no meio ambiente.

\section{Metodologia}

O presente artigo utiliza-se de seleção de publicações, através de pesquisa bibliográfica, buscando fundamentação teórica acerca dos principais processos de desinfecção de efluentes eficazes e passíveis de aplicabilidade, considerando custos, capacidade operacional, desenvolvimento tecnológico, facilidade de aquisição de equipamentos e insumos, necessidade de pessoal qualificado, entre outros. Propondo mudanças baseadas nos resultados observados e considerando as peculiaridades da realidade brasileira.

Neste interim justifica-se a escolha deste método, pois de acordo com Pereira et al., (2018) este é passível de discussão dos resultados obtidos em relação aos autores consultados nas referências, sendo interessante pois possibilita comparação entre as pesquisas anteriores sobre o tema e conclusão ou várias conclusões em relação a um determinado assunto.

A análise de publicações nacionais e internacionais, tais como, evidências em bases de dados científicas eletrônicas, incluindo artigos, relatórios técnicos, englobando as áreas da política, saúde e saneamento, norteou a pesquisa elucidando as principais técnicas, vantagens e viabilidade de aplicação na remodelagem dos processos de desinfecção de efluentes no Brasil. 


\section{Possibilidades da Transmissão do SARS-CoV-2 em Esgotos e Efluentes- A Realidade Brasileira}

Os coronavírus fazem parte da família de vírus RNA Coronaviridae, que infectam uma variedade de mamíferos e aves, dividido em três grupos, I e II isolados em mamíferos e o III encontrado em aves. Sendo endêmicos, replicam-se no trato respiratório e entérico. As primeiras amostras identificadas em humanos, foram isoladas em 1960, em pacientes portadores de doenças infecciosas sem maiores gravidades (Cavanagh, 2002).

Estruturalmente o SARS-CoV-2 possui no material genômico de RNA fita simples sentido positivo, servindo diretamente para síntese proteica, proporcionando maior velocidade na geração de novas cópias de vírus na célula infectada, seu tropismo para expressão da proteína ACE2 (da sigla em inglês: angiotensin-converting enzyme 2), direcionam sua replicação em células calciformes, ciliadas do nariz, pneumócitos II, esôfago, enterócitos e conjuntivais superficiais (Choi et al., 2020).

Gupta et al., (2020) comprovou que nas fezes foram encontrados vírus ativos após um período prolongado, apesar da negatividade dos esfregaços respiratórios, pois em 5\% dos casos, as fezes foram testadas positivas 26 dias após a alta, determinando que a carga viral no trato respiratório tende a esgotar-se mais rapidamente do que no trato intestinal.

Segundo autores, Cavanagh (2002), World Health Organization (2020), Wigginton e Boehm (2020), a transmissão pessoa a pessoa do SARS-CoV-2 deve-se a sua presença no trato respiratório de pessoas infectadas e ocorre através de gotículas e aerossóis de secreções. No entanto, o vírus SARS-CoV-2, também foi detectado nas fezes e na urina de pessoas infectadas levantando questionamento que uma possível transmissão oral/fecal, ainda não pode ser descartada (Soares et al., 2020).

Os resultados destes estudos seguem acompanhados com grande preocupação, conforme Daughton (2020), despertando a necessidade de identificar as melhores estratégias para tratamento e gestão de águas residuais e resíduos, de forma a acautelar-se de situações danosas para população e meio ambiente a médio e longo prazo.

No Brasil, $43 \%$ da população possui esgoto coletado e tratado, enquanto $12 \%$ utilizam-se de fossa séptica, ou seja, 55\% possuem tratamento considerado adequado; $18 \%$ têm seu esgoto coletado e não tratado, o que pode ser considerado como um atendimento precário; e 27\% não possuem coleta nem tratamento, isto é, sem atendimento por serviço de coleta sanitário. (Soares et al., 2020). Segundo Collivignarelli (2020), em águas residuais a capacidade de sobrevivência do SARS-CoV-2, permanece incerta e os resultados disponíveis acerca da atividade do agente etiológico no ambiente são limitados, sugerindo investigação do impacto de condições externas, tais como, temperatura, $\mathrm{pH}$ e tempo de retenção, na persistência do vírus no ambiente aquático. Requerendo execução de testes visando avaliar sua vitalidade, ainda não realizados, até o momento.

A concentração e sobrevivência de vírus de modo geral, em efluentes dependem de fatores como: carga viral da doença na população; composição do esgoto; temperatura; tipo de tratamento do esgoto e da disposição final dos efluentes, o qual pode ser realizado em rios, solo, disposição oceânica etc. (Rollemberg; De Barros; De Lima, 2020).

Um estudo preliminar sobre a presença de SARS-CoV-2 em águas residuais após tratamento secundário e terciário, evidenciou que $11 \%$ das amostras após tratamento com lodo ativado convencional resultaram positivas para RNA do SARSCoV-2 (Balboa, et al., 2020). Neste sentido a OMS recomendou uma etapa de desinfecção para evitar a liberação de vírus em receptores de corpos aquáticos (World Health Organization, 2020).

Tal recomendação, frustra-se na legislação brasileira, dada a não exigência de etapas de desinfecção de efluentes domésticos, portanto, raramente é praticada no Brasil, segundo a Cartilha de Recomendações para Prevenção do Contágio da Covid-19 pela Água e por Esgoto Doméstico, elaborado Sala técnica do Saneamento (Brasil, 2020). Atrelado ao fato que no Brasil muitas unidades de saúde (públicas e privadas) interligam seus esgotos sanitários diretamente na rede, embora haja a recomendação de que disponham de sistema próprio de tratamento possibilitando realizar a etapa de inativação de patógenos antes de lançar as águas residuais no sistema de esgotamento geral (Rollemberg; De Barros; De Lima, 2020). 
Diante do contexto apresentado na realidade brasileira, sem precedentes nos estudos realizados por pesquisadores nos demais países (Austrália, Espanha, França, Itália, China), com realidades diversas no tratamento de efluentes, Soares et al. (2020), esclarece ser imprudente afirmar a inviabilidade da transmissão do SARS-CoV-2 por vias hídricas, quando consideradas as condições sanitárias e ambientais apresentadas no Brasil.

Nesse ínterim, Soares et al. (2020), recomenda que a atuação das empresas prestadoras dos serviços de saneamento precisa estar alinhada com a necessidade de controle sobre os sistemas de esgotamento sanitário e capazes de orientar as medidas preventivas de contágio, mitigando os riscos e empreendendo esforços para enfrentamento da doença no país. Paralelamente, Da Silva Ferreira, et al. (2020), complementa sobre as incertezas face ao novo coronavírus, a inevitabilidade e urgência de investimentos na área de saneamento como medidas preventivas e corretivas envolvendo pesquisas e inovações não apenas pela urgência da crise atual, mas como critério de responsabilidade social, visto que o despejo de esgoto sem o adequado tratamento degrada a qualidade das águas receptoras, causam impacto na saúde da população, além de comprometer abastecimento humano, balneabilidade, irrigação, dentre outros.

\section{Estado da Arte dos Métodos de Desinfecção de Efluentes}

Na situação atual de pandemia, considerando a patogenicidade do agente etiológico da COVID-19, ainda que estudos descrevam poucas evidências de transmissão através dos efluentes, são necessárias revisões das técnicas de desinfecção mais utilizadas para sistemas de abastecimento e tratamento de efluentes precedentes à destinação para corpos d'água (Soares, et al. 2020).

Dentre os métodos mais aplicados no Brasil, destacam-se como principais processos desinfetantes para efluentes a aplicação de hipoclorito de sódio, sais de ferrato (VI), radiação ultravioleta (UV), dióxido de cloro e ozonização.

a) Hipoclorito de sódio

O processo de desinfecção mais aplicado nos sistemas de tratamento de efluentes e tratamento de águas para abastecimento, utiliza produtos à base de cloro, em estados sólidos, líquidos ou gasosos (Funasa, 2014). A alta eficiência do hipoclorito usado na concentração de $12 \%$ na etapa de desinfecção, advém do seu equilíbrio que, quando em meio aquoso, formando ácido hipocloroso $(\mathrm{HOCl})$ e ácido hidroclorídrico $(\mathrm{HCl})$, como mostrado pela equação:

$$
\mathrm{Cl} \_2+\mathrm{H} \_2 \mathrm{O} \leftrightharpoons \mathrm{HOCl}+\mathrm{HCl}
$$

Similarmente, compostos como hipoclorito de cálcio e sódio apresentam mecânicas de equilíbrio que resultam na produção de espécies $\mathrm{HOCl}$ -

$$
\begin{gathered}
\mathrm{Ca}(\mathrm{OCl})_{2}+2 \mathrm{H} \_2 \mathrm{O} \leftrightharpoons \mathrm{Ca}^{2+}+2 \mathrm{HOCl}+2 \mathrm{OH}^{-} \\
\mathrm{NaOCl}+\mathrm{H}_{2} \mathrm{O} \leftrightharpoons \mathrm{Na}^{+}+\mathrm{HOCl}+\mathrm{OH}^{-}
\end{gathered}
$$

Ademais, o ácido hipocloroso, como um ácido fraco, dissocia-se em íon hipoclorito (OCl-) como mostrado pela seguinte equação:

$$
\mathrm{HOCl} \leftrightharpoons \mathrm{H}^{+}+\mathrm{OCl}^{-}
$$

A soma das concentrações de $\mathrm{HOCl}$ e $\mathrm{OCl}$ - é chamada de cloro livre, disponível para a desinfecção. Métodos colorimétricos como DPD (N, N-dietil-p-fenilenodiamina) ou ortotolidina e métodos potenciométricos de ORP (potencial de oxidação/redução) são capazes de indicar concentrações de cloro residual livre em efluentes (Feng; Smith; Bolton, 2007).

O baixo-custo operacional, fácil manutenção - proporcionada pela simplicidade de bombas dosadoras - e simples procedimentos de preparo das soluções tornam o hipoclorito de sódio ou cálcio alternativas direcionadas à implementação de sistemas para desinfecção mais simplificados. Embora o consumo de energia por parte de bombas dosadoras, manutenção da concentração das soluções hipercloradas a serem dosadas bem como o potencial corrosivo das soluções, suscita desvantagens à técnica (Tian, 2019). 
É cabível considerar a importância do monitoramento das concentrações de cloro residual livre nas águas desinfetadas, pois, ainda que não há legislações vigentes quanto aos valores máximos permitidos à destinação, a hipercloração da água poderá causar a formação de trialometanos (THMs) - como triclorometano, bromodiclorometano e iodobromoclorometano - compostos com potencial carcinogênico ao ser humano e danosos ao meio ambiente (Feng; Smith; Bolton, 2007).

Segundo Pianowski e Janissek (2003), a utilização da mesma sistemática no tratamento de afluentes e efluentes na aplicação do cloro, não é boa alternativa, pois, os objetivos são diversos, no tratamento de águas para abastecimento o cloro é aplicado de forma a manter um residual fixado garantindo a inativação de coliformes em longos trajetos da estação de tratamento até o usuário final. Em efluentes, a finalidade é inativação imediata dos microrganismos patogênicos presentes, com o menor residual de cloro possível tanto livre como combinado.

b) Dióxido de Cloro

$\mathrm{O}$ dióxido de cloro $\left(\mathrm{ClO}_{2}\right)$, possui amplas propriedades bactericidas, virucidas, esporocidas e algicidas, por este motivo é muito estudado para aplicação como desinfetante de água de abastecimento e efluentes domésticos, inibidor de crescimento de algas e ao contrário do cloro, suas propriedades oxidantes e desinfetantes, permanecem pouco alteradas em uma ampla faixa de pH entre 4 a 10. (Ribeiro, 2001).

Ainda segundo Ribeiro (2001), o dióxido de cloro tem capacidade de oxidar outras substâncias através de um mecanismo de transferência de um único elétron, onde o $\mathrm{ClO}_{2}$ é reduzido a clorito sem produção de hipoclorito ou cloro gasoso. Também é capaz de oxidar os precursores dos trialometanos, apresentando reduzida formação de subprodutos organoclorados, quando aplicado adequadamente.

O dióxido de cloro possui alta instabilidade no estado gasoso, e pode tornar-se explosivo caso sua concentração no ar ultrapasse 10\% em volume. Tendo como vantagem não sofrer hidrólise em contato com a água, portanto permanecendo estável em temperaturas e iluminação controladas (inferior a $25^{\circ} \mathrm{C}$ e ambiente preservado de luz). Não obedecendo essas condições citadas o gás pode sofrer uma aceleração de decomposição formando subprodutos considerados nocivos ao ambiente e saúde humana, tais como o clorito e o clorato (Pianowski; Janissek, 2003).

c) Ferrato (VI)

A aplicação de sais de ferrato (VI) na desinfecção de efluentes ganharam crédito como uma alternativa ao uso de cloro devido aos subprodutos formados pela combinação do cloro com substâncias orgânicas, potencialmente mutagênicas e carcinogênicas. O ferrato (VI), possui propriedades pré oxidantes e coagulantes, considerado seguro e eficiente no tratamento de águas e efluentes (De Luca; Deus; De Luca, 2002).

$\mathrm{O}$ ferrato (VI) apresenta a fórmula molecular FeO42- e constitui-se em forte oxidante, estudos conduzidos por Manoli (2019), revelaram que sob condições ácidas $(\mathrm{pH}<2,0)$, seu potencial redox é maior que do ozônio, representando o desinfetante/oxidante mais forte utilizado no tratamento de águas e efluentes.

A versatilidade do ferrato (VI) como instrumento para sistemas de tratamento viabiliza a maior eficiência em processos assim como a redução dos tamanhos das instalações necessárias ao tratamento, pois é produzido por via eletrolítica, com a vantagem de poder ser gerado in loco. (Talaiekhozani; Talaei; Rezania, 2017).

As propriedades oxidantes do ferrato (VI) quando destinado a corpos d'água o tornou um prospecto substituto para outros agentes oxidantes e desinfetantes atualmente utilizados, como cloro, ozônio e permanganato (Ghernaout; Elboughdiri, 2019). O baixo impacto do ferrato (VI) se deve a sua baixa reatividade com íons brometo ( $\mathrm{Br}^{\wedge}$-), dificultando a formação de coprodutos brominados após o processo de desinfecção, assim como, a redução de coprodutos de desinfecção do cloro, quando utilizados de forma conjunta em processos de tratamento (Karin et al., 2020). 
No âmbito da remoção de cargas virais, Manoli et al. (2019) demonstra a capacidade do ferrato (VI), como desinfetante, à desativação de vírus, indicando os danos à proteína dos capsídeos e ao genoma como possíveis causadores da desativação dos patógenos.

Entretanto, o ferrato (VI) ainda não encontra uso em larga escala, ainda que estudos demonstrem resultados encorajadores, tais como, melhor rendimento que o hidróxido de ferro $\left(\mathrm{Fe}(\mathrm{OH}) \_3\right)$ como floculante em tratamentos de água, redução da DBO (Demanda Biológica por Oxigênio), e significativo decréscimo na formação de THM, apresentando resultados 1500 vezes inferiores. Considerado como o produto químico mais ecológico usado no tratamento de águas e efluentes, o ferrato (VI), apresenta-se como alternativa à pré-cloração, necessitando aprofundamento de pesquisas em escala real, para a garantia de redução de THM (Karim et al., 2020).

O ferrato (VI), figura como um agente desinfetante emergente, oferece uma perspectiva futura em um mundo póspandemia, no qual haverá a necessidade de maior empenho em políticas e pesquisas inovadoras voltadas ao saneamento e desinfecção de efluentes, denotando necessidade de ampliação dos estudos e desenvolvimento tecnológico da aplicabilidade e viabilidade do ferrato (IV) para uso em larga escala (Ghernaout; Elboughdiri, 2019).

d) Radiação ultravioleta (UV)

A radiação ultravioleta (UV), é capaz interagir no DNA e RNA celular, alterando ou degradando sua composição, portanto, a incidência de radiação UV sobre superfícies e meios líquidos é capaz de atuar como desinfetante. (Rangel; Silva; Guede, 2009).

Segundo Scopacasa (2008), a utilização de radiação UV-C é conhecida desde o final do século XIX. Equipamentos baseados em radiação UV voltada à desinfecção da água utilizam - em termos gerais - lâmpadas de vapor de mercúrio ou LEDs nas faixas de UV-B e UV-C, conferindo menor custo, redução do consumo de energia e maior durabilidade. A aplicação dos raios UV-C para desinfecção, denotam vantagens, visto que a eficácia dos atuais produtos de limpeza decresce de acordo com a ampliação do seu uso, estimulando progressiva resistência microbiana ao passo que a desinfecção por radiação UV é isenta de provocar resistência em agentes patogênicos, sejam bactérias ou vírus, além da não geração de subprodutos e coprodutos tóxicos ao solo e corpos d'água naturais, curto tempo de contato e uma melhor ação antiviral em relação a outras técnicas de desinfecção por seu mecanismo de ação de inativação afetar o código genético, desestruturando os ácidos nucleicos viral (Rubio; Vieira, 2020).

As unidades de desinfecção de esgotos sanitários com radiação ultravioleta podem fundamentar-se em diversas modelagens de distribuição, sendo o mais prático, menos dispendioso e de maior eficácia a fixação de lâmpadas ultravioletas acima da água e em paralelo ao fluxo de escoamento, no entanto, este processo apresenta-se pouco eficiente em águas residuais, pois a turbidez determinada por partículas suspensas, impedem penetração da radiação, reduzindo a eficácia da desinfecção (Moreira, 2007).

Admite-se também que consequências do uso destes equipamentos emissores de UV-C, cabendo capacitação e cautela em seu manuseio, por isso não se recomenda uso de UV-C como germicida por pessoas não habilitadas (Sgardi; Do Carmo; Rosa, 2012).

e) Ozônio

De acordo com Rosado (2014), em um meio natural o ozônio é um gás produzido naturalmente na estratosfera pela ação fotoquímica dos raios UV sobre as moléculas de oxigênio. Esses raios, com $\lambda<200 \mathrm{~nm}$, são suficientemente intensos separando os dois átomos que compõem a molécula de $\mathrm{O}_{2}$, produzindo assim o oxigênio atômico. O gás também pode ser produzido através de três principais métodos: exposição do $\mathrm{O}_{2}$ luz ultravioleta, eletrólise do ácido perclórico e por método de descarga eletroquímica, essa última a mais comum. 
Segundo Lapolli (2005), devido sua extrema instabilidade, a produção de ozônio através de geradores, deve ocorrer in locus e imediato, basicamente o gás pode ser produzido mais comumente pela descarga eletroquímica, com utilização de geradores (Bavasso et al., 2020).

A ozonização é uma técnica de oxidação química que promove a decomposição completa ou parcial de poluentes orgânicos de difícil degradação. Tais poluentes orgânicos, quando sofrem decomposição, formam $\mathrm{CO} 2$ e H2O; e quando sofrem decomposição parcial são transformados em moléculas menores (Costa, 2007).

As características oxidativas, tem alta eficiência, no entanto há desvantagens relacionadas à necessidade de realizar contínuas dosagens de ozônio, devido sua instabilidade em meio líquido, permanecendo ativo por pouco tempo. A dose inicial típica de ozônio é de 3 a $10 \mathrm{mg} / \mathrm{L}$ e o tempo de contato é de $10 \mathrm{~min}$, o que resulta em valores de CT (Concentração X Tempo) entre 30 e $100 \mathrm{mg}$ min/L. O ozônio decompõe-se espontaneamente na água por meio de mecanismos complexos que envolvem a geração de radicais livres hidroxilas (Rollemberg; De Barros; De Lima, 2020).

A utilização de ozônio foi avaliada para a descontaminação de efluentes para inativação de vírus entéricos, in vitro, coxsackievirus B5 (CVF, CVEnv1 e CVEnv2), adenovírus (HAdV), echovirus 11 (EV) resultando em diminuição na concentração de todos os vírus testados com diferentes níveis de sensibilidade (Tecnologias, 2020).

O ozônio é capaz de inativar o SARS-CoV-2 através de seu potencial de oxidação, ocasionando danos ao capsídeo do vírus. Atuando, portanto como desinfetante químico (Rollemberg; De Barros; De Lima, 2020).

As aplicações de ozônio para desinfecção de águas e efluentes não serem difundidas no Brasil, sendo mais empregado na Europa, e a sua utilização em efluentes ainda não é considerada uma tecnologia consolidada (Jäger et al., 2018). Limitações como a baixa solubilidade do ozônio, que dificulta a devida difusão e transferência de massa da fase gasosa para a líquida, levando a uma baixa razão entre concentração de ozônio/quantidade de matéria degradada, alto custo de implementação dos sistemas de ozonização, contribuem para restringir a aplicabilidade em larga escala do ozônio em estações de tratamento de água e esgotos (Mahmoud; Freire, 2007).

\section{Recomendações para Desinfecção de Efluentes Frente à Pandemia de COVID-19 no Brasil}

Estudos acerca da etapa de desinfecção dos efluentes sanitários são cada vez mais proeminentes, não apenas devido ao alerta disparado pela pandemia do novo coronavírus, mas também, pela crescente deterioração das fontes de abastecimento de água para consumo humano. O objetivo principal da desinfecção é neutralizar os microrganismos patogênicos, que podem estar presentes no efluente tratado, tornando segura a água receptora de uso posterior, pois estes contêm uma série de patógenos que são excretados nas fezes de indivíduos infectados e nem sempre os processos convencionais de tratamento de esgotos são suficientes para a remoção desses microrganismos.

No Brasil o déficit sanitário demanda esforços e investimentos que contemplem técnicas inovadoras de monitoramento do comportamento das espécies aquáticas, como meio de detectar precocemente alterações que poderão tornarse irreversíveis para sua sobrevivência. A seleção da técnica mais adequada à desinfecção é de suma importância, pois, em maior ou menor grau, a maioria dos processos estudados anteriormente para determinam algumas desvantagens para o meio ambiente, saúde humana e capacidades técnicas-operacionais das estações de tratamento de efluentes no Brasil.

As recomendações para remodelação da desinfecção de efluentes, de acordo com os estudos realizados e sintetizados, demonstram através das variáveis, tendência para investimento e concentração de esforços para adoção do processo de associação do ferrato (VI), com percentual reduzido de cloro. O ferrato (VI) ainda comprova seu alto potencial oxidante, perdendo apenas para a radiação UV - cujos custos são elevados - e dentre os processos estudados o ferrato (VI), é o único considerado químico verde, sendo seu subproduto $\mathrm{FeO}^{2-}$, inerte e atóxico para o meio ambiente, consequentemente para os seres vivos. 
Entretanto, é razoável considerar o baixo registro de anterioridade (Bujanovic, 2016) da aplicação de sistemas de desinfecção de ferrato (VI) fora do âmbito laboratorial ou em plantas piloto, de tal maneira, a implementação dessa substância e a infraestrutura não o configura como uma recomendação viável a curto prazo.

Conjuntamente, os processos de incidência de radiação ultravioleta e ozonização para o tratamento de desinfecção da água exigem a instalação de equipamentos custosos, tanto para a aquisição e manutenção dos sistemas, exigindo a devida cautela e capacitação dos colaboradores responsáveis nas estações de tratamento. Destaca-se que a radiação UV, como radiação não-ionizante representa um risco físico à segurança do trabalho. A necessidade da utilização de filtros para o aumento da eficiência da desinfecção por UV - partindo da redução da turbidez do efluente - cria maiores demandas de retrolavagens e troca de materiais filtrantes.

A desinfecção com derivados de cloro é, na atualidade, a mais difundida no Brasil. A aplicação de dióxido de cloro, todavia, possui implicações logísticas negativas, assim como a grande alocação espacial dentro das estações de tratamento e a existência do risco de vazamento de gás, exigindo providências acerca da asseguração da segurança do trabalhador e comunidades circunvizinhas. A utilização de soluções hipercloradas de hipoclorito de sódio representam uma opção de baixo risco operacional e simples manutenção.

A problemática acerca da geração de trialometanos (THMs), gerados pelas altas concentrações de cloro residual livre gera uma preocupação acerca da adoção dessa técnica, entretanto, a calibração apropriada dos sistemas dosadores (bombas volumétricas oscilantes) poderá garantir a concentração ótima de cloro residual livre com o fim de minimizar a geração de THMs. O monitoramento físico-químico das águas receptoras dos efluentes se definiria como uma medida de acompanhamento das concentrações de THMs bem como a elaboração e execução de ações corretivas frente a desacordos com as legislações ambientais vigentes.

\section{Considerações Finais}

Processos de desinfecção de efluentes alheios à realidade vigente, desconsiderando a conjuntura estrutural dos sistemas de tratamento de efluentes e saneamento no Brasil, podem agregar recomendações desassociadas e não exequíveis. Ainda que tecnologias emergentes de desinfecção de águas residuais - em especial as de origem doméstica e hospitalar apresentem resultados significativos, segundo a literatura científica, sistemas tradicionais de desinfecção podem ser revistos, associando outros processos, aplicando controles de qualidade ambiental mais rigorosos, na perspectiva de ampliação da captação de esgotos e modernização das estações de tratamento de efluentes.

A aplicação de soluções hipercloradas na saída dos esgotos e nas estações de tratamento é viável no atual panorama brasileiro dada sua fácil aplicação. O desenvolvimento de estudos visando sua associação com ferrato (VI), constitui uma técnica promissora, digna de maior aprofundamento para comprovação, em especial, considerando o monitoramento ambiental desenvolvendo diretivas para ajuste e calibração através de dispositivos dosadores do hipoclorito e do ferrato (VI).

Ainda que hajam incertezas deflagrados pela magnitude, transcendência e vulnerabilidade vivenciadas em situação pandêmica, decerto, as transformações por ela causadas retiram os planejamentos corretivos do protagonismo trazendo os princípios preventivos à frente. Ainda mais tendo como argumentos as potencialidades mutagênicas do Sars-CoV-2, assim como outros microrganismos, exigindo a reflexão de maior rigor em processos relacionados à higiene e saneamento, não só como garantia da saúde pública, mas como proteção aos impactos ambientais.

A remodelação dos processos de desinfecção de efluentes no Brasil, constitui uma reflexão premente que instigam a necessidade de trabalhos futuros, tais como, pesquisa de campo em escala real na aplicabilidade dos métodos e monitoração dos seus resultados; Investimentos na área de captação e tratamento de esgotos domésticos no país, assim esforços das autoridades públicas na compreensão e efetivação de apoio e fomento às instituições que direcionam suas pesquisas para área. 


\section{Referências}

Balboa, S., Mauricio-Iglesias, M., Rodríguez, S., Martínez-Lamas, L., Vasallo, F. J., Regueiro, B., \& Lema, J. M. (2020). The fate of SARS-CoV-2 in wastewater treatment plants points out the sludge line as a suitable spot for incidence monitoring. MedRxiv.

Bavasso, I., Montanaro, D., Di Palma, L., \& Petrucci, E. (2020). Electrochemically assisted decomposition of ozone for degradation and mineralization of Diuron. Electrochimica Acta, 331, 135423.

Bujanovic, L. N., Cekerevac, M., Tomic, M., Zdravkovic, M., \& Đokovic, M. S. (2016). Pilot plant for treatment of raw drinking water with high content of arsenic using ferrate (VI). Acta Technica Corviniensis-Bulletin of Engineering, 9(2), 19.

Cavanagh, D., Mawditt, K., Welchman, D. D. B., Britton, P., \& Gough, R. E. (2002). Coronaviruses from pheasants (Phasianus colchicus) are genetically closely related to coronaviruses of domestic fowl (infectious bronchitis virus) and turkeys. Avian pathology, 31(1), 81-93.

Collivignarelli, M. C., Collivignarelli, C., Miino, M. C., Abbà, A., Pedrazzani, R., \& Bertanza, G. (2020). SARS-CoV-2 in sewer systems and connected facilities. Process Safety and Environmental Protection.

Costa, J. B. D. (2007). Avaliação ecotoxicológica de efluente de tratamento secundário de esgoto sanitário após desinfecção com ácido peracético, cloro, ozônio e radiação ultravioleta (Doctoral dissertation, Universidade de São Paulo).

Da Silva Ferreira, A. D., Pimentel, C. P., Moscon, A., Curty, T. N., \& De Oliveira, M. D. (2020). Sars-Cov-2 No Esgoto: Métodos De Detecção E Tratamento. Revista Ifes Ciência, 6(1), 15-22.

Daughton, C. (2020). The international imperative to rapidly and inexpensively monitor community-wide Covid-19 infection status and trends. The Science of the Total Environment, 726, 138149.

De Luca, S. J., Deus, A. B. S. D., \& De Luca, M. A. (2002). Desinfecção de efluentes tratados com ferrato (IV). Engenharia sanitária e ambiental. Rio de Janeiro: Abes. 7(3) (2002), 103-108.

De Mello, R. R. P. B., Villardi, R. M., Mello, S. C. R. P., \& de Miranda, M. G. (2020). Desafios No Acesso À Água E Saneamento Básico No Brasil E O Controle Da Covid-19. Revista Augustus, 25(51), 281-293.

De Tecnologias, C. D. I. (2020). Ministério da Saúde.

Feng, Y., Smith, D. W., \& Bolton, J. R. (2007). Photolysis of aqueous free chlorine species (HOCl and OCl) with 254 nm ultraviolet light. Journal of Environmental Engineering and Science, 6(3), 277-284.

Fernandes, N. (2020). Economic effects of coronavirus outbreak (COVID-19) on the world economy. Available at SSRN 3557504

Ghernaout, D., \& Elboughdiri, N. (2019). Water Disinfection: Ferrate (VI) as the Greenest Chemical-A Review. Applied Engineering, 3, 171-180.

Gupta, S., Parker, J., Smits, S., Underwood, J., \& Dolwani, S. (2020). Persistent viral shedding of SARS-CoV-2 in faeces-a rapid review. Colorectal Disease.

Jäger, T., Alexander, J., Kirchen, S., Dötsch, A., Wieland, A., Hiller, C., \& Schwartz, T. (2018). Live-dead discrimination analysis, qPCR assessment for opportunistic pathogens, and population analysis at ozone wastewater treatment plants. Environmental Pollution, $232,571-579$.

Karim, A. V., Krishnan, S., Pisharody, L., \& Malhotra, M. (2020). Application of Ferrate for Advanced Water and Wastewater Treatment. In Advanced Oxidation Processes-Applications, Trends, and Prospects. IntechOpen.

Komatsu, B. K., \& Menezes-Filho, N. (2020). Simulações de Impactos da COVID-19 e da Renda Básica Emergencial sobre o Desemprego, Renda, Pobreza e Desigualdade: Policy Paper.

Lapolli, F. R., Hassemer, M. E. N., Camargo, J. G., Damásio, D. L., \& Lobo-Recio, M. Á. (2005). Desinfecção de efluentes sanitários através de dióxido de cloro. Engenharia Sanitária e Ambiental, 10(3), 200-208.

Mahmoud, A., \& Freire, R. S. (2007). Métodos emergentes para aumentar a eficiência do ozônio no tratamento de águas contaminadas. Química Nova, 30(1), 198-205.

Manoli, K., Maffettone, R., Sharma, V. K., Santoro, D., Ray, A. K., Passalacqua, K. D., \& Sarathy, S. (2019). Inactivation of murine norovirus and fecal coliforms by ferrate (VI) in secondary effluent wastewater. Environmental Science \& Technology, 54(3), 1878-1888.

Moreira, R. M., Pinto, A. M., Mesnier, R., \& Leclerc, J. P. (2007). Influence of inlet positions on the flow behavior inside a photoreactor using radiotracers and colored tracer investigations. Applied radiation and isotopes, 65(4), 419-427.

Paiva, R. F. D. P. D. S., \& Souza, M. F. D. P. D. (2018). Associação entre condições socioeconômicas, sanitárias e de atenção básica e a morbidade hospitalar por doenças de veiculação hídrica no Brasil. Cadernos de Saúde Pública, 34, e00017316.

Pereira, A. S., Shitsuka, D. M., Parreira, F. J., \& Shitsuka, R. (2018). Metodologia da pesquisa científica.

Pianowski, E. H., \& Janissek, P. R. (2003). Desinfecção de efluentes sanitários com uso de cloro: avaliação da formação de trialometanos. Sanare: Revista Técnica da Sanepar, 20(20). PRADO, Marcelo et al. Análise de subnotificação do número de casos confirmados da COVID-19 no Brasil. 2020.

Rangel, M. G., Silva, P. B., \& Guede, J. R. A. (2009). Led-Iluminação de Estado Sólido. São José do Campos.

Ribeiro, L. F. (2001). Aplicação de dióxido de cloro como alternativa para desinfecção de esgotos sanitários tratados através de lagoas de estabilização. 
Research, Society and Development, v. 10, n. 2, e35310212691, 2021 (CC BY 4.0) | ISSN 2525-3409 | DOI: http://dx.doi.org/10.33448/rsd-v10i2.12691

Rollemberg, S., de Barros, A. N., \& de Lima, J. P. M. (2020). Avaliação da contaminação, sobrevivência e remoção do coronavírus em sistemas de tratamento de esgoto sanitário. Revista Tecnologia, 41(1).

Rosado, F. G. L. (2014). Aplicação da ozonização e de processos oxidativos avançados na degradação dos fármacos paracetamol e dipirona presentes em efluentes aquosos simulados.

Rubio, J. C. C., \& Vieira, L. M. (2020). Determinação Das Variáveis De Exposição Para Um Sistema De Desinfecção Por Radiação UV. Acta Mechanìca et Mobilitatem, 5(1), 24-28.

Scopacasa, V. A. (2008). Introdução à Tecnologia de LED. Revista LA_PRO, 5-10.

Sgardi, F. C., do Carmo, E. D., \& Rosa, L. F. B. (2012). Radiação ultravioleta e carcinogênese. Revista de Ciencias Medicas, 16(4/6).

Soares, A. F. S., Nunes, B. C. R., Costa, F. C. R., de Morais Silva, L. F., \& Souza, L. P. Vigilância do sistema de esgotamento sanitário e o novo coronavírus (SARS-CoV-2) no Brasil: uma discussão necessária.

Tian, Y., Jiang, Y., Liu, Q., Dong, M., Xu, D., Liu, Y., \& Xu, X. (2019). Using a water quality index to assess the water quality of the upper and middle streams of the Luanhe River, northern China. Science of the Total Environment, 667, 142-151.

Uhr, J. G. Z., Schmechel, M., \& Uhr, D. D. A. P. (2016). Relação entre saneamento básico no Brasil e saúde da população sob a ótica das internações hospitalares por doenças de veiculação hídrica. Revista de Administração, Contabilidade e Economia da Fundace, 7(2).

Wigginton, K. R., \& Boehm, A. B. (2020). Environmental engineers and scientists have important roles to play in stemming outbreaks and pandemics caused by enveloped viruses.

World Health Organization. (2020). Water, sanitation, hygiene and waste management for COVID-19: technical brief, 03 March 2020 (No. WHO/2019NcOV/IPC_WASH/2020.1). World Health Organization. 